\title{
Detector Leakage Gas LPG Based on Telegram Notification Using Wemos D1 and MQ-6 Sensor
}

\author{
Uci Rahmalisa ${ }^{1}$, Anita Febriani ${ }^{2}$, Yuda Irawan ${ }^{3 *}$ \\ ${ }^{1,3}$ Department of Information System, STMIK Hang Tuah Pekanbaru, Pekanbaru, Indonesia \\ ${ }^{2}$ Department of Technical Information, STMIK Hang Tuah Pekanbaru, Pekanbaru, Indonesia \\ Email: ${ }^{1}$ ucirahmalisa89@gmail.com ${ }^{1}$, nitasuheri@gmail.com², yudairawan89@gmail.com³ \\ *Corresponding Author
}

\begin{abstract}
Gas leaks most often come from the gap between the mouth of the tube and the regulator so that it can cause pollution to the polluted room. This is due to the seal that serves as a sealing gap between the gas cylinder valve and the regulator not working. This seal serves to close and isolate the gap between the regulator and the upper mouth of the gas cylinder so that gas leakage can be avoided, or it could also be caused by rat bites on the hose which can cause gas to leak. For this reason, a LPG gas leak detection device can be made remotely. Created a LPG gas leak detection system based on Wemos D1 microcontroller using telegram notification. The whole tool is divided into several parts which consist of mq-6 sensor, ESP8266-01S module, wemos d1 microcontroller, and buzzer. This tool works when the ESP8266-01S module searches for the nearest internet network and the mq-6 sensor detects Ipg gas, from the ESP826601S module and mq-6 sensor then to the Wemos D1 microcontroller to process, from the Wemos D1 microcontroller then activates the buzzer as a warning alarm that then transfer data through the ESP8266-01S module to the website and give notification of a gas leak to the smartphone of the user of the device. The mq-6 sensor functions if the gas content value is above 80. The results show that the gas content value is more than 80 as detected lpg gas, because it has tested the system and when there is no lpg gas the gas content value is less than 80 .
\end{abstract}

Keywords- Sensor Mq-6, wemos d1, Module ESP8266-01S, Buzzer

\section{INTRODUCTION}

Based on the test results of the National Standardization Agency (BSN), as much as $66 \%$ of the gas cylinders tested were found to be unfit for use was studied by zhang [1]. Along with the increasing use of LPG gas, the quality of gas cylinder products has decreased, and the need for supervision of gas cylinder products from the manufacturer, so it cannot cause danger was studied by dae [2]. Gas leaks most often come from the gap between the mouth of the tube and the regulator so that it can cause pollution to the polluted room. This is due to the seal that serves as a sealing gap between the gas cylinder valve and the regulator not working was studied by saeed [3].

The current technological development has been so rapid and the use of technology has become increasingly important and needed in the aspects of human life, including in the field of LPG gas leakage. Indonesian society as users of LPG gas cylinders is increasing from year to year was studied by irawan [4]. This situation occurs because of the implementation of a government program, namely the conversion of kerosene to LPG gas with the aim of diverting subsidies and the use of kerosene by the community to LPG was studied by jiang [5]. Users of LPG gas cylinders are not only limited to urban communities, but now they have penetrated into remote areas of the countryside was studied by kodali [6]. The LPG gas cylinder that is most widely used by the community is the $3 \mathrm{~kg}$ size. Because the price is affordable and easy to find in residential areas was studied by wang [7]

The risk of using LPG gas that often leaks is in the gas cylinder or gas installation. Based on the test results of the National Standardization Agency for Indonesia (BSN), as many as $66 \%$ of the tested gas cylinders were not suitable for use was studied by nasaruddin [8]. Along with the increasing use of LPG gas, the quality of gas cylinder products has decreased, as well as the need for supervision of gas cylinder products from the producer side, so that they cannot cause harm. The gas leak most often comes from the gap between the nozzle and regulator so that it can cause polluted indoor pollution was studied by qiang [9]. This is because the seal which functions as a gap seal between the gas cylinder valve and the regulator is not working was studied by nasarudin [10]. This seal serves to close and isolate the gap between the regulator and the upper mouth of the gas cylinder so that gas leakage can be avoided was studied by muhardi [11], or it could be caused by a mouse bite on the hose which can cause gas to leak was studied by Vijayalakshmi [12]. The solution given in this research is the manufacture of an LPG gas leak detection device that can be detected remotely. Because from the results of the interviews I conducted with the public, most people do not yet understand the characteristics of a gas leak was studied by Irawan [13]. When they want to turn on the gas stove, the community does not first check the condition of the gas that is leaking, which can cause an explosion and cause a fire was studied by mateev [14].

In the design of this tool, to detect the presence or absence of LPG gas, an MQ-6 gas sensor which has been widely produced and widely circulated in the market is used, as a controller and data processor using Wemos D1 was studied by sohor [15]. In addition, this system is also able to send information to the user's cellphone in the event of a LPG gas leak in the form of a short message to TELEGRAM was studied by ordila [16]. This tool is also equipped with a buzzer which indicates that the gas detected by the sensor in 
the room contains more and more. This could indicate that the room has an LPG gas leak was studied by wahyuni [17].

It is hoped that with this solution, the community as consumers will feel comfortable in using LPG gas. In addition, knowing LPG gas leaks early can prevent more crucial things, such as explosions and fires was studied by Shrestha [18].

For its application, this tool will use Wemos D1 and MQ6 sensors. Therefore, the authors make a final research with the title "Lpg Gas Leakage Detector Based on Telegram Notification Using Wemos D1 and Mq-6 Sensor"Housework is one of the most time-consuming activities was studied by was studied by Varma [19]. Not only that, this activity is carried out every day, and of course when there is neglected homework it will be something that is lacking was studied by sun [20]. One of the household chores that is a concern for this problem is folding dried clothes was stuied by irawan [21]. When there are a lot of clothes, this will certainly take the time to fold and tidy up the clothes quickly and neatly, so that time for other activities is wasted was studied by wahyuni [22].

From the above problems, a solution appears to ease wasted activity and time, for that a tool model is made that can help in folding clothes quickly with automatic labor was studied by makiko [23]. The purpose of this research is to design a model for a clothes folding device based on Arduino Uno and Gear Servo was studied by irawan [24]. It is hoped that this tool can provide benefits for solving solutions in terms of folding clothes in a relatively fast and neat time without having to fold manually by hand was studied by gao [25]. So far, many people who fold clothes still use manual methods, namely using their bare hands was studied by sun [26].

Based on the majority of people still folding clothes manually was studied by niveditha [27], in this study the author will design and make a clothes folding device based on the Arduino Uno, the mechanism is fast moving with the help of Gear Servo and other components. It is hoped that this tool can help shorten the time for folding clothes was studied by fitriastuti [28].

\section{METHODS}

In this stage the researcher uses the prototype method, because this method is a method that is widely used by software developers. The essence of this method is the work of a model development into a final system.

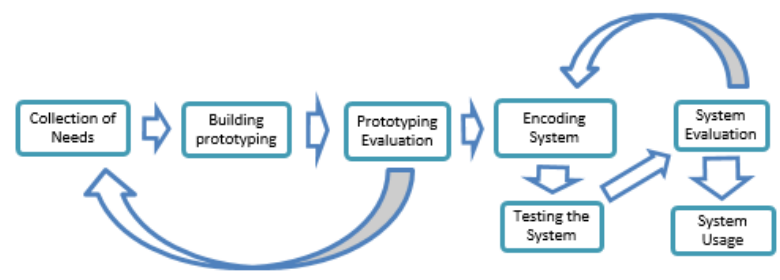

Fig.1. Prototype Model

The following are the stages of making a prototype method, namely:
1. Collection of Needs

Here the researcher analyzes the needs in the design of the control system to be built. Among them is the selection of the required hardware and software. In this case the researchers used the Wemos D1 microcontroller as the main hardware and Telegram as an intermediary for communication between smartphones and hardware.

\section{Building Prototyping}

In this case the researcher describes the input and output formats that will be produced by the control system created. Here the researcher describes the input and output schemes that will be received by Wemos D1.

\section{Evaluation of Prototyping}

Furthermore, after the prototyping development stage, the researcher defines the format and requirements of the overall control system, identifies all requirements, and an outline of the system to be built, for example the communication path between the Wemos D1 microcontroller and the Telegram platform.

\section{Encoding the System}

In this stage the prototyping that has been agreed upon is translated into an appropriate programming language as a process for inputting commands that will be received on the microcontroller. In this system, the programming language used is $\mathrm{C}++$ using the Arduino IDE software.

\section{System testing}

In this stage, the modules that have been made are combined and tested to find out whether the system that has been built is in accordance with the design and whether there are still errors or not. Testing using android is testing carried out directly by the user.

\section{System evaluation}

System evaluation is not prototyping evaluation, system evaluation is evaluating the finished system or software and hardware whether it is in accordance with the wishes or not. If not, then the system will be revised again and return to stages 4 and 5 . If the system is said to be OK, the system is ready to continue at the next stage.

\section{Use of the system}

This stage is the final stage of creating a control system using the Prototyping Model method. At this stage the readymade tools that have passed the test are ready for use.

\section{IMPLEMENTATION}

Implementation is one of the stages in system development, where this stage is the stage of placing the LPG gas leak detection system so that it is ready for operation and can be seen as an effort to realize the system that has been designed.

\section{A. Implementation of LPG Gas Detector}

Testing the Wemod D1 system on the LPG gas leak detection system can be done in the following steps:

1. Connect the electric current source to the LPG leak detector hardware circuit. 


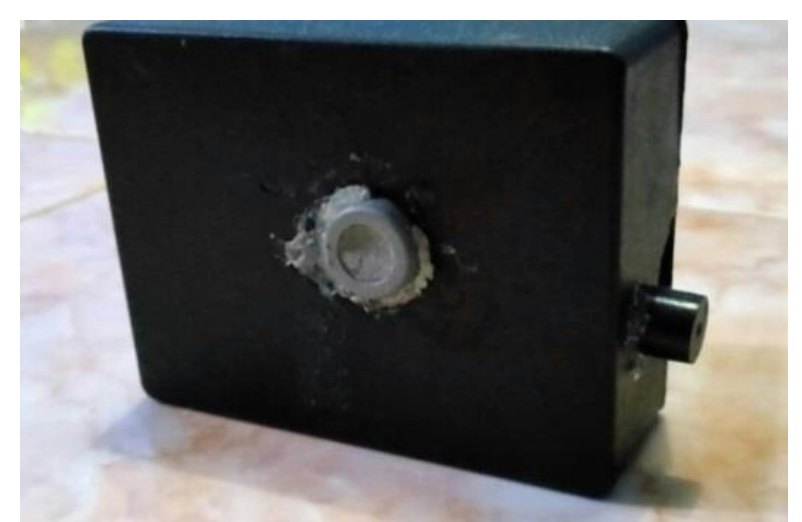

Fig.2. Implementation of LPG Gas Leak Detector System Testing

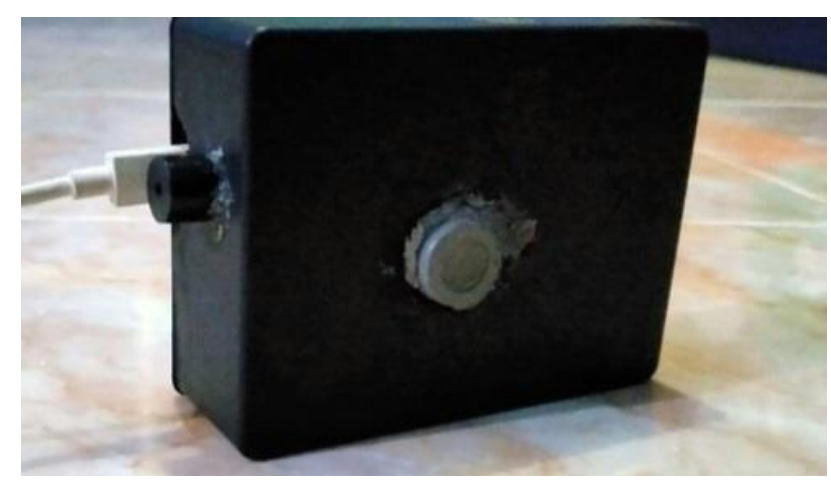

Fig. 3. The device is connected to an electric current

2. After that the LPG gas leak detection system will turn on like its supporting devices, namely Wemos D1, Sensor MQ-6.

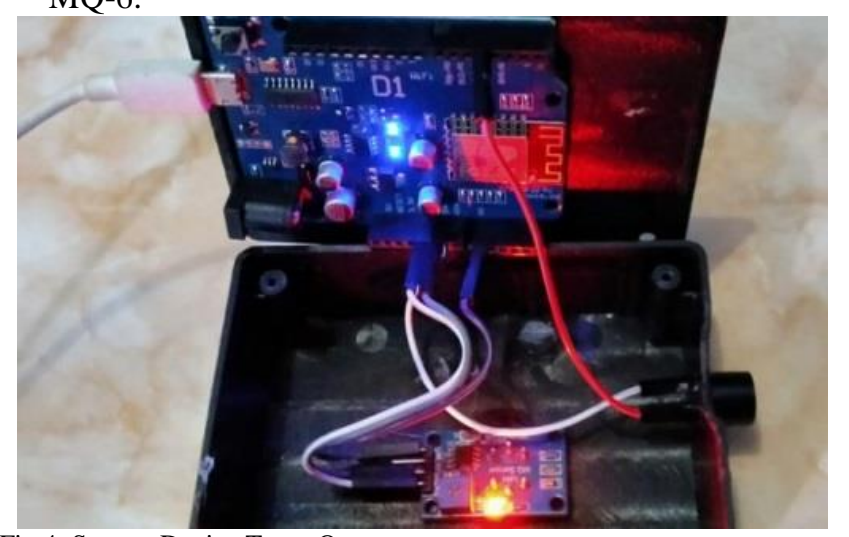

Fig.4. System Device Turns On

3. Then the LPG gas leak detection system will connect the internet network that has been set on the Wemos D1 microcontroller.

4. After the LPG gas leak detection system is connected to the internet, the MQ-6 sensor is active and ready to detect LPG gas around the installed system.

5. When the LPG gas leak detection system detects LPG gas, the warning alarm is activated automatically, then the system will send a notification that there is a gas leak and the system will send the gas level value data to the website which can be seen by anyone.

\section{B. Testing Systems on the Prototype}

Tests conducted to test the system on a prototype designed with a gas lighter.
TABLE I TESTING OF GAS LEAK DETECTION SySTEMS

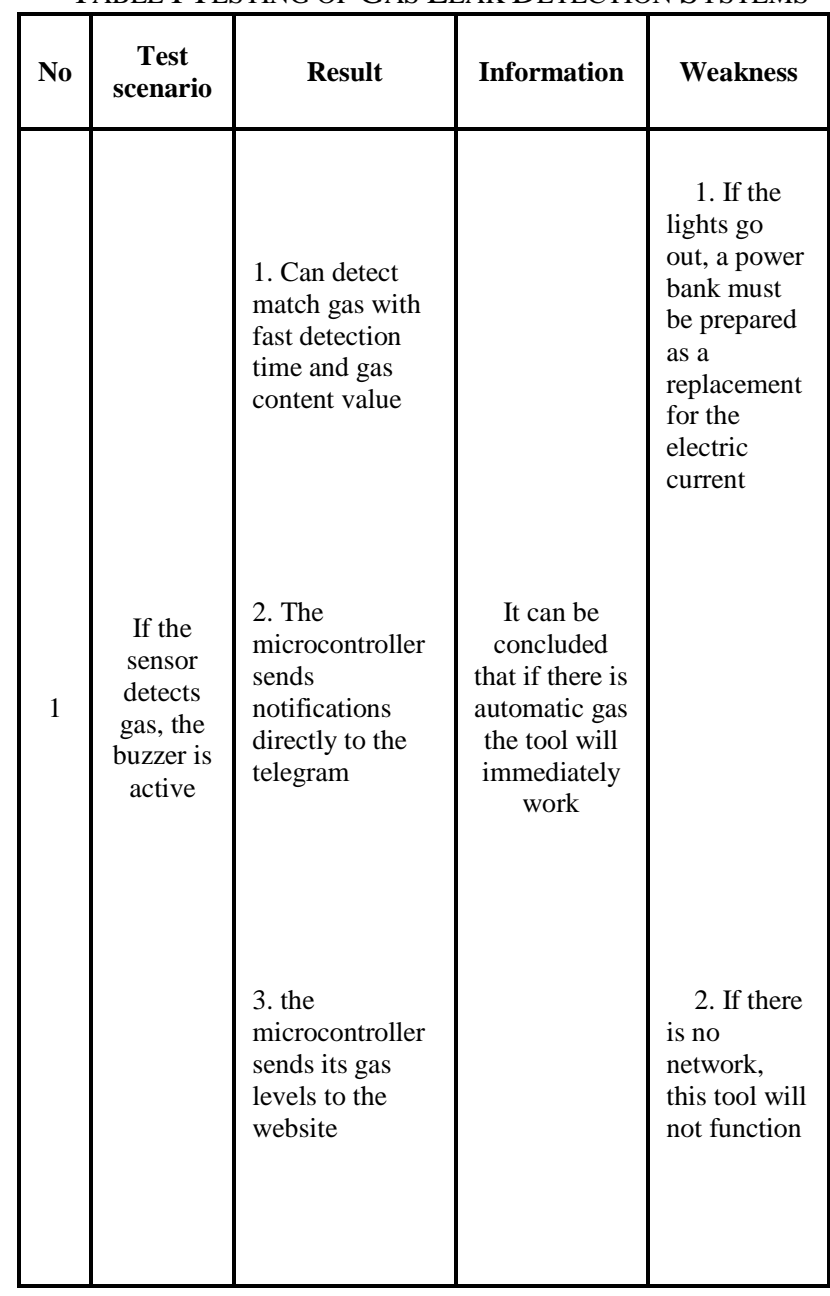

\section{Mq-6 Sensor Testing}

Tests using a sample of match gas leaked. When the gas level value read by the Mq-6 Sensor is below 80, there is no gas leak and when the gas level value read by the Mq- 6 sensor is above 80 , a gas leak is detected. The Mq- 6 sensor will send data to the Wemos D1 microcontroller.

TABLE II TESTING THE MQ-6 SENSOR

\begin{tabular}{|c|c|c|c|}
\hline Gas Level & Sensor & Buzzer & Condition \\
\hline$<80$ & Not active & Not active & No Gas Leaks \\
\hline$>80$ & Active & Active & Gas Leaks Detected \\
\hline
\end{tabular}

The results of testing the gas level value of the mq- 6 sensor showed different conditions that occurred. In a condition where there is no gas leak, the gas level is less than 80 , while the condition when there is a gas leak, the gas level is more than 80 . From the results of this test automatically when there is no gas leak, the buzzer is not active. In the results of testing the gas level value of the mq- 6 sensor in a condition where a gas leak is detected, the buzzer is automatically active as a warning alarm then the system will send a warning notification of a gas leak and the system will 
send the gas level value to the website in graphic form. Researchers used a gas level value of more than 80 as detected kobocoraN gas, because the researcher had tested the system and when there was no gas leak the gas level value was less than 80 .

\section{CONCLUSION}

Based on the results of the analysis, design and implementation that has been done. Then several conclusions can be drawn including the following: the LPG gas leak detection system uses the Wemos D1 Microcontroller as a data processor, the Mq-6 sensor as a gas leak detector, a Buzzer as a warning alarm, and can function properly so that it is more efficient in detecting gas leaks. The LPG gas leak detection system can make it easier for housewives to monitor gas leaks around the area where the tool is installed. With the gas leak detection system, it can send information to the smartphone via the telegram application for situations outside the home.

\section{REFERENCES}

11 H. Zhang, F. Zhuang, Y. Li and H. Gong, "The reliability of the process of lifetest of the Aerospace Photoconductive Infrared Detector," 2013 International Conference on Quality, Reliability, Risk, Maintenance, and Safety Engineering (QR2MSE), Chengdu, 2013, pp. 1015-1017, doi: 10.1109/QR2MSE.2013.6625737.

[2] Dae-Sik Lee, Sang-Woo Ban, Minho Lee and Duk-Dong Lee, "Micro gas sensor array with neural network for recognizing combustible leakage gases," in IEEE Sensors Journal, vol. 5, no. 3, pp. 530-536, June 2005, doi: 10.1109/JSEN.2005.845186.

[3] M. S. Saeed and N. Alim, "Design and Implementation of a Dual Mode Autonomous Gas Leakage Detecting Robot," 2019 International Conference on Robotics,Electrical and Signal Processing Techniques (ICREST), Dhaka, Bangladesh, 2019, pp. 7984, doi: 10.1109/ICREST.2019.8644075.

[4] Irawan, Y., Fernando, Y., \& Wahyuni, R. Detecting Heart Rate Using Pulse Sensor As Alternative Knowing Heart Condition. Journal of Applied Engineering and Technological Science (JAETS),2019, 1(1), pp 30-42.

[5] Wahyuni, Refni; Rickyta, Aditya ; Rahmalisa, Uci ; Irawan, Yuda Home Security Alarm Using Wemos D1 And HC-SR501 Sensor Based Telegram Notification. Journal of Robotics and Control (JRC), 2020, 2.3: 200-204.

[6] X. Yi and B. Jiang, "Comparisons and analysis of the equipments and methods for SF6 gas leakage detection," 2009 IEEE 9th International Conference on the Properties and Applications of Dielectric Materials, Harbin, 2009, pp. 204-207, doi: 10.1109/ICPADM.2009.5252472.

[7] Irawan, Yuda. Moving Load Robot Using Wifi Network and Android Based. Journal of Robotics and Control (JRC), 2020, 2.3: 217-220.

[8] R. K. Kodali, R. N. V. Greeshma, K. P. Nimmanapalli and Y. K. Y Borra, "IOT Based Industrial Plant Safety Gas Leakage Detection System," 2018 4th International Conference on Computing Communication and Automation (ICCCA), Greater Noida, India, 2018, pp. 1-5, doi: 10.1109/CCAA.2018.8777463.

[9] Qiang Wang and Xiaowei Wang, "Underwater natural gas pipeline leakage detection based on interferometric fiber optic sensor in experiment-scale," 2010 Chinese Control and Decision Conference, Xuzhou, 2010, pp. 257-260, doi: 10.1109/CCDC.2010.5499075.

[10] N. M. B. Nasaruddin, I. Elamvazuthi and N. H. H. B. M. Hanif, "Overcoming gas detector fault alarm due to moisture," 2009 IEEE Student Conference on Research and Development (SCOReD), Serdang, 2009, pp. 426-429, doi: 10.1109/SCORED.2009.5442980.

[11] Muhardi, Muhardi, et al. "Design Of Web Based LMS (Learning Management System) in SMAN 1 Kampar Kiri Hilir." Journal of Applied Engineering and Technological Science (JAETS) 1.2 (2020): 70-76.

[12] J. Vijayalakshmi, G. Puthilibhai and S. R. L. Siddarth, "Implementation of Ammonia Gas Leakage Detection \& Monitoring
System using Internet of Things," 2019 Third International conference on I-SMAC (IoT in Social, Mobile, Analytics and Cloud) (I-SMAC), Palladam, India, 2019, pp. 778-781, doi: 10.1109/ISMAC47947.2019.9032577.

[13] Irawan, Yuda. "Implementation Of Data Mining For Determining Majors Using K-Means Algorithm In Students Of SMA Negeri 1 Pangkalan Kerinci." Journal of Applied Engineering and Technological Science (JAETS) 1.1 (2019): 17-29.

[14] V. Mateev, I. Marinova and Z. Kartunov, "Automatic System for LiIon Battery Packs Gas Leakage Detection," 2018 12th International Conference on Sensing Technology (ICST), Limerick, 2018, pp. 1316, doi: 10.1109/ICSensT.2018.8603567.

[15] Sohor, Suherman, Et Al. Rancang Bangun Tempat Sampah Otomatis Mengunakan Mikrokontroler Dan Sensor Ultasonik Dengan Notifikasi Telegram. Jurnal Ilmu Komputer, 2020, 9.2: 154-160.

[16] Ordila, Rian, et al. Penerapan Alat Kendali Kipas Angin Menggunakan Microcontroller Arduino Mega 2560 Dan Sensor Dht22 Berbasis Android. Riau Journal Of Computer Science, 2020, 6.2: 101-106.

[17] Wahyuni, Refni; IRAWAN, Yuda. Web-Based Employee Performance Assessment System in PT. Wifiku Indonesia. Journal of Applied Engineering and Technological Science (JAETS), 2020, 1.2: 60-69.

[18] S. Shrestha, V. P. K. Anne and R. Chaitanya, "IoT Based Smart Gas Management System," 2019 3rd International Conference on Trends in Electronics and Informatics (ICOEI), Tirunelveli, India, 2019, pp. 550-555, doi: 10.1109/ICOEI.2019.8862639.

[19] A. Varma, Prabhakar S and K. Jayavel, "Gas Leakage Detection and Smart Alerting and prediction using IoT," 2017 2nd International Conference on Computing and Communications Technologies (ICCCT), Chennai, 2017, pp. 327-333, doi: 10.1109/ICCCT2.2017.7972304.

[20] J. Sun, Y. Li and X. Yan, "The design of automatic detection processing device of gas leakage based on the MB95204K," 2011 International Conference on Electrical and Control Engineering, Yichang, 2011, pp. 1807-1809, doi: 10.1109/ICECENG.2011.6058104.

[21] Irawan, Yuda, Et Al. Pemanfaatan Modul Gsm Dan Modul Gps Pada Sistem Keamanan Sepeda Motor Menggunakan Smartphone Berbasis Arduino Uno. Jurnal Teknologi Dan Open Source, 2020, 3.1: 90-100.

[22] Wahyuni, Refni; Irawan, Yuda. Web-Based Heart Disease Diagnosis System With Forward Chaining Method (Case Study Of Ibnu Sina Islamic Hospital). Journal Of Applied Engineering And Technological Science (Jaets), 2019, 1.1: 43-50.

[23] Makiko Kawada, Tadao Minagawa, Eiichi Nagao, Mitsuhito Kamei, Chieko Nishida and Koji Ueda, "Advanced monitoring system for gas density of GIS," 2008 International Conference on Condition Monitoring and Diagnosis, Beijing, 2008, pp. 363-368, doi: 10.1109/CMD.2008.4580302.

[24] Irawan, Yuda. Penerapan Data Mining Untuk Evaluasi Data Penjualan Menggunakan Metode Clustering Dan Algoritma Hirarki Divisive Di Perusahaan Media World Pekanbaru. Jurnal Teknologi Informasi Universitas Lambung Mangkurat (JTIULM), 2019, 4.1: 13-20.

[25] S. Gao, R. Pei and G. Liu, "Magnetic Circuit Design Based on Circumferential Excitation in Oil-Gas Pipeline Magnetic Flux Leakage Detection," 2009 Second International Symposium on Computational Intelligence and Design, Changsha, 2009, pp. 550553, doi: 10.1109/ISCID.2009.144.

[26] J. Sun, Y. Li and X. Yan, "The design of automatic detection processing device of gas leakage based on the MB95204K," 2011 International Conference on Electrical and Control Engineering, Yichang, 2011, pp. 1807-1809, doi: 10.1109/ICECENG.2011.6058104.

[27] S. Nivedhitha, A. P. Padmavathy, U. S. Susaritha and M. G. Madhan, "Development of Multipurpose Gas Leakage and Fire Detector with Alarm System," 2013 Texas Instruments India Educators' Conference, Bangalore, 2013, pp. 194-199, doi: 10.1109/TIIEC.2013.41.

[28] Fitriastuti, F., Rahmalisa, U., \& Girsang, A. S. (2019, March). Multicriteria decision making on succesfull of online learning using AHP and regression. In Journal of Physics: Conference Series (Vol. 1175, No. 1, p. 012071). IOP Publishing. 
This page is intentionally left blank 